\title{
THE PROFESSION
}

\section{political science on the web: prospects and challenges}

\section{michael nentwich}

Institute of Technology Assessment, Austrian Academy of Sciences, 1030 Vienna, Strohgasse 45/5, Austria.

E-mail: mnent@oeaw.ac.at

doi:10.1057/palgrave.eps.2210161

\begin{abstract}
The first part of this contribution provides a short overview on the state-ofthe-art of Internet use in political science. In the second part, a few trends are outlined that will have an impact on the field, followed by a more detailed discussion of possible implications of electronic publishing. In the conclusion, a few recommendations to political science professionals are spelled out recommending how the field should react to this development.
\end{abstract}

Keywords electronic publishing; E-journals; living reviews; virtual libraries; cyberscience

\section{INTRODUCTION: THE STATE-OF-THE-ART OF INTERNET USE IN POLITICAL SCIENCE}

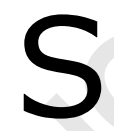

ince the early 1980 s, the scholarly community has been witnessing a considerable increase in the use of information and communication technologies (ICT). The networked PC, E-mail, the Internet, on- and off-line databases, the World Wide Web, electronic publications, discussion lists and newsgroups, electronic conferences, digital libraries and knowledge robots ('knowbots') are but a few of the trends that increasingly influence the daily work of the scientific community. As opposed to 'traditional' science and research that has done without networked computers, the notion of 'cyberscience' designates the use of these ICT-based applications and services for scientific purposes (Nentwich, 2003).

Political scientists are no exception from this general trend. They profit a lot from the Internet as indispensable resources are increasingly online; for example, legal and preparatory texts, documents by institutions and groups participating in political decision-making (such as parties, NGOs, administrative bodies) and statistical data are now on the Web. For sure, political scientists still carry out interviews in the field, filter through printed material and watch the traditional media. But the fact that the majority of players in politics now have their own Website (offering much 
more than they would have given away in pre-Internet times) and that many have their public diaries (blogs) makes the work of a political scientist at the same time easier and different to before. Together with the availability of bibliographic databases and, increasingly, electronic full text of scholarly articles, a considerable part of the work of a political scientist has moved to cyberspace.

In all political science sub-fields, you find link collections and resource collections of various kinds. While there is a considerable variation, the homepages of the research institutes and of the scholarly associations in the field as well as of conferences have long reached a high standard of information depth. A number of projects were initiated to build up common resources in the field. For instance, an Italian group advocated Hyperpolitics (De Rosa, 2000; Calise and Lowi, 2000), a worldwide resource depository based on a common thesaurus (but it is still unrealised). Mainly designed for facilitating teaching is the German project PolitikOn, ${ }^{1}$ but it also has some potential to develop into a cooperative research tool. A model portal for resources in the field of international affairs is $\mathrm{CIAO}^{2}$ from Columbia University Press. It publishes a wide range of scholarship writing from 1991 onwards, including working papers from university research institutes, occasional paper series from NGOs, foundation-funded research projects, and conference proceedings. The German project of an encompassing virtual library for political science $\mathrm{ViFaPol}^{3}$ provides, in cooperation with the EZB Regensburg (see below), a comprehensive list of journals, but also has newsletters and other resources. SOSIG ${ }^{4}$ the British portal for the social sciences, edited by the British Library of Political and Economic Science (at LSE), has an important politics section with numerous links, sorted to subsections such as 'Political Parties' or 'International Relations'.

\section{'Cyberscience is in the making. Generally speaking, political science is following the general trend of most fields of research'.}

Besides those explicitly mentioned above, there are literally hundreds of journals and databases in the field, now also available online. It is difficult to get hard facts as there is no international observation board or similar that would make surveys at regular intervals. There are, however, a number of resources that indicate the wealth of E-journals worldwide. The latest annual report (for 2005) of the well-known international Electronic Journals Library $(E Z B)^{5}$ of currently 362 universities (Universitätsbibliothek Regensburg, 2006), for instance, gives the following numbers for political science-related journals, see Table 1.

The current EZB number for July 2006 rose to 1732 . The ViFaPol lists 758 journals and yearbooks; SOSIG fourteen online full-text journals and the electronic journal subscription database MUSE ${ }^{6}$ has 28 politics titles on offer. The central directory for open access journals $(\mathrm{DOAJ})^{7}$ provides access to fifty-one free, full-text, quality-controlled scientific and scholarly journals in the field of politics.

\section{SOME TRENDS THAT WILL SHOW AN IMPACT ON THE FIELD}

Cyberscience is in the making. Any account of the existing status quo should be modified by an assessment of likely future trends. Generally speaking, political science is following the general trend of most fields of research. 
Table 1: Politics journals

\begin{tabular}{lccc}
\hline & All journals & Journals with fees & Free journals \\
\hline Print \& online & 1.403 & 627 & 776 \\
Online only & 193 & 14 & 179 \\
\hline
\end{tabular}

Source: regensburg database.

\section{E-JOURNALS WILL TAKE OVER}

In particular, already today most working paper series are online only and there is a growing tendency towards more E-journals (i.e., journals that do not also appear in print, but only digitally). Many believe that in the not-so-distant future, there will be no print journals any more because they are too costly and fast electronic delivery to one's desktop is what most scholars desire anyway (Keller, 2001). Furthermore, it is to be expected that soon many other printed academic publications will be electronic only, in particular conference proceedings, some types of text books and research reports (Nentwich, 2003: 356).

\section{NEW JOURNAL FORMATS}

One particular interesting trend is the concept of living reviews. ${ }^{8}$ These are entirely Web-based, peer-reviewed journals, publishing reviews of research on core themes relating to a particular field of study. The articles in a living reviews journal are solicited from specialists in their fields and are directed towards the scientific community at or above the graduate student level. The articles provide up-to-date critical reviews of the state of research in the fields they cover. They also offer annotated insights (and where possible, active links) into the key literature and describe online resources available in these fields. One of the most important features of living reviews is that its articles are kept up-to-date by their authors. This is the significance of the word 'living' in the journal's title. Living reviews will be used by its readers as a database, as an encyclopaedia or as a research briefing, in addition as a review journal. The goal of these journals is to develop their articles into a carefully screened and edited, well-integrated, topical set of hypertext documents that, taken together, form a valuable research tool for scholars of the particular field. Political science is at the forefront when it comes to implementing this concept, which has been originally developed in physics. One such journal is already online in the field of European integration research, ${ }^{9}$ another one is about to be founded in another political science sub-field, namely democracy research.

There are other interesting new publishing formats, in particular hybrid or crossover publications (Nentwich, 2003: $327 \mathrm{ff}$.). While the concepts of a journal or an edited book were stable in the preInternet age, Web technologies produce new publication types that are hybrid forms that are neither journals nor books, but something in between. For instance, there is a successful Website called TRANS $^{10}$ that has features of a journal (it has issues, a peer-review process and publishes individual articles), of proceedings (each issue is linked to a conference) and of an edited volume (there is an introduction by the editor and you can even buy a printed version of the whole), but in fact it is all of them at once and even more. Usually, an issue of a print journal or a book can only be published once all contributions are delivered and ready for print. The online world allows

michael nentwich european political science: 002007 
successive publishing: once a few articles for an issue are ready, they will be published; late-comers may join over the following years; the editors may even decide to add further articles unrelated to the original conference. Yet another interesting concept is the virtual journal: it is an online collection of relevant articles from a broad range of source journals in a field. From a user's perspective, the virtual journal looks and feels like a 'real' journal, with contents list, abstracts, editorials, etc. ${ }^{11}$ No such journal is yet to be found in political science but is an attractive concept also for the social sciences because in a virtual journal emerging topics that have not yet their own journal may be treated in a user-friendly and comprehensive way.

\section{HYPERTEXT AND MULTIMEDIA}

So far, political scientists are rather 'conservative' when it comes to the use of hypertext and multimedia, although the Web and its capabilities have been around for some time. Most publications in the field are what is called 'linear' texts to be read from beginning to end. There are only very few examples of hypertexts so far, consisting of many text modules, linked together in a sort of textual Web (e.g., Nentwich, 2000). However, it may be argued that as soon as the majority of all pertinent texts are available online and freely accessible, new types of texts are likely, which make use of already published material by linking pieces of them together in a hypertext format. Online 'hyperbooks' or 'hyperbases' may emerge that consolidate the available knowledge in a field. I assume that these novel publication formats will first emerge as teaching tools and as encyclopaedias. In addition, multimedia elements such as audio files (e.g., parts of original interviews or speeches) or short video sequences (e.g., of political events) may soon become common place as enhancements of standard text articles in E-journals. Arguably, this additional online material has the potential to make an argument both more convincing (as regards the relationship between empirical data and results) and more transparent (as regards the way conclusions are reached).

\section{OPEN ACCESS}

One further important general trend in the field of academic publication is open access, and it is also important for the field of political science (May, 2005). Still, most journals in the field are only accessible to those fortunate enough to be employed by or to study at an institution wealthy enough to afford subscription rates for all necessary journals. The open access movement is growing in importance and well under way. For instance, the list of subscribers to the Berlin Declaration $^{12}$ is already impressive (literally, hundreds of universities and large research institutions endorse it); the ROMEO database ${ }^{13}$ shows that an evergrowing proportion of publishers allow their authors to make their publications also available via freely accessible institutional repositories; many funding institutions subscribe already to the open access philosophy (most recently the British Wellcome Trust ${ }^{14}$ ) and last but not the least, the Commission on scientific information in the digital age asks all publicly (including European) funded research to be made accessible under the open access regime. ${ }^{15}$ In the field of political science in particular, many institutional repositories have already seen the light of the cyberday (e.g., ERPA ${ }^{16}$ ) and a few open access services are available that allow researchers independently from their institutions to upload their papers for the benefit of the community, such as SSRN ${ }^{17}$ or AEI. ${ }^{18}$ 


\section{WHAT IS THE IMPACT OF E- PUBLISHING ON POLITICAL SCIENCE?}

Based on the above account of the status quo and the presentation of a few important trends, we are now in a position to address the most interesting questions regarding possible implications of the obvious development towards cyberpolitical science.

\section{DIRECT CONSEQUENCES OF E-PUBLISHING}

Starting with the move towards electronic publishing, it seems obvious, as compared to the pre-Internet age, that important resources necessary for the daily work of political scientists are much more accessible now. Many of the sources such as newspapers, databases and journals are now available in the WWW, although many of them are only accessible for the fortunate scholars at a wealthy home base (see above). Furthermore, working papers and a selection of journal articles are easily accessible. In fields such as physics, where books do not play an important role in formal academic communication, it is less of a problem that books and contributions to edited volumes are not yet or only seldom available online. By contrast, in political science a considerable part of publications are still book based. It will take still some time before these contributions to the scholarly debate will be as easily accessible as journal articles.

In some respects, the speed of publication has increased, in particular by the use of E-mail for sending different versions of manuscripts around or of Webbased software for the editing process. The latter can also contribute to a more transparent handling and processing of submissions as authors (as well as editors and reviewers) may check the state of a particular paper in the evaluation chain.

\section{'Over the last decade or so, publishing in political science has been gradually changing towards a culture of pre-online publishing'.}

Furthermore, electronic publication formats that do not rely on issues but publish as soon as a manuscript has been accepted also contribute to much shorter turn-around times (from submission to publication).

Over the last decade or so, publishing in political science has been gradually changing towards a culture of pre-online publishing. Most printed papers are available earlier in some online version, for instance as working papers. Some authors even actively promote their forthcoming articles and books by the use of dedicated Websites. In this respect, political science is becoming more similar to physics, mathematics and computer sciences where the E-print culture is well established since the early days of the Internet. ${ }^{19}$

\section{THE PRINT-NEGLECT-EFFECT}

As long as very little material and publications were available online only, it could be, and was, largely neglected by the majority of political scientists, because they could expect that at some point all the virtual stuff would be printed anyway. No doubt, the share of online material is growing fast, but we are not yet at the point where all academic publications in the field are available online (not to speak of free access as called for by the open access movement). However, I have no doubt that in the not-so-distant future the majority of all 
scientifically necessary textual material will be online.

This may have important consequences: one may observe in other fields that those publications that are not available online - and those that are less accessible because of price tags attached to them - are less and less used. This is particularly true among students and the younger generation of scholars who have experienced intensive contact with the Internet during their studies. There seems to be a threshold of online availability, which once reached in a field leads to the perception that 'everything is online' and hence there would be no need to look up offline material - which is just the opposite of our initial observation of early Internet times with regard to online material. We have not yet reached that point in political science, but I cannot see any reason why it will be any different for this particular field. Efforts have to be made, both in training the Internet generation of scholars and in digitising and making available online potentially all the research literature in the field.

\section{CHALLENGES AND OPPORTUNITIES IN QUALITY CONTROL}

One of the frequent arguments against electronic publishing always was and still is that quality control is worse in the online world and therefore one should not trust these new resources. Wellestablished and renowned peer-reviewed online journals and even high-quality online working paper series prove, however, that a comparable level of quality to the print world is feasible in the online world as it is in the print world. Quality control is, in principle, medium-independent.

What is more, the Internet provides new ways of assessing quality that would not have been practical in the offline world. While in the print age, pre-publication evaluation was centre stage, there

\section{'Quality control is, in principle, medium- independent'.}

are many more opportunities if publications are all digitally available. For instance, online peer commenting on publications can be organised: a forum attached to an article could enhance the level and transparency of the post-publication communication processes; the collected comments may serve prospective readers as an indicator whether the article is worth reading. Other instruments for post-publication quality control in the wider sense are rating mechanisms (similar to the user rating of online booksellers like Amazon). Commenting may also be combined in the pre-publication phase with standard peer review, whether double-blind or not-anonymous. These tools have not yet been implemented in many cases, but they may contribute in the future to a changing publishing environment in political science (for a comprehensive discussion of new quality control tools, see Nentwich, 2005).

\section{LONG-TERM ARCHIVING}

When it comes to E-publishing (independently of the field), a very important point is long-term archiving. This was rather straightforward for print publications with a highly specialised traditional system of preservation. For digital publications, such an efficient system still has to be established because it is very important to guarantee that every element of the scholarly debate (i.e., if it was quoted and referred to by later or parallel contributions) stays available indefinitely for retrieval and reference. While many of the most-pressing technical problems are still unsolved, we are witnessing the beginning of some concerted action in 
this area. It seems that each institution and each field is somehow responsible to organise their own archives, but not many have yet accepted that challenge. In some respects, however, such archives are not only the key to a sustainable publishing culture, but also a solution to the above-mentioned aim of establishing one-stop access to the resources of a field. Archiving is coupled with another important task, namely setting and implementing standards with regard to changing URLS, that is, the Internet addresses. URLS of digital resources should never change unless appropriate forwarding mechanisms are in place or permanent addresses are used, such as the system of digital object identifiers (DOIs).

\section{INNOVATIVE PUBLISHING MODELS AND THE SCIENCE CULTURE}

Despite some dangers (e.g., the aforementioned danger of loss of digital knowledge), new opportunities arise with innovative publishing models. We have already mentioned some of them in the previous section, such as 'living' reviews journals; the use of hypertext; the inclusion of further multimedia material and data in the online version of an article, etc. Political science is not yet far on this road, but some promising projects are nonetheless well under way.

Let us briefly discuss whether for instance the 'living reviews' model has the potential to change the science culture in political science. I think it is safe to describe political science as a field that is much less 'cumulative' than, say, physics. This is partly due to the nature of the object of research, as society and politics are constantly changing, they are 'moving targets'. Research results related to previous political developments are not necessarily applicable to later events and circumstances or different settings

\section{"'Living reviews" could become the focal point of debate in the field about future directions of research'.}

in other parts of the world. There is not yet a 'grand theory' connecting all subfields of political science in a common framework, whose details only have to be filled in on the basis of further research. Yet, nevertheless, scholars specialising in different areas of politics, time and place do learn from each other by way of comparison, and they have found some overarching concepts that can be built upon by others. Unlike in other fields, there is no systematic 'review' culture in political science in the sense that the 'state-of-the-art', the sum of collective knowledge, is being summarised in an accessible, transparent and critical format that would allow the community to discover neglected areas, to draw from the common knowledge of the field, or from empirical material. In other words, there seems to be no real 'core' of the field, no common 'construction site', but rather many of them that are only loosely connected and often duplicate each other. In this situation, the concept of 'living reviews' may make a difference and impact on the culture of knowledge sharing in the field as well as on targeting research. In an ideal scenario, there would be constantly updated review articles in each field of specialisation, summarising what is known and what is not, where future research should focus on, etc. By this token, 'living reviews' could become the focal point of debate in the field about future directions of research. As the first 'living reviews' journal in political science has only just started, we cannot draw any conclusions yet: the proof of the pudding is in the eating.

michael nentwich european political science: 002007 


\section{LOST IN HYPERSPACE?}

A significant challenge has not yet been fully recognised by the academic community: political science - along with any other fields - still lacks an efficient means to tackle the danger of being confused by the complexity and variety of digital resources. While there are a few attempts to develop high-quality one-stop services for political science resources, none of them is yet convincing, as they usually only provide annotated, more or less ordered link collections, but no coherent and systematic framework (the 'living reviews' concept is an exception here). For instance, publishing digitally offers new opportunities when it comes to assessing the quality of research contributions (apart from ex ante control mechanisms such as peer review), in particular by ex post instruments such as citation counts, rating and commenting (see above). Based on these new possibilities, sophisticated automated filtering systems could be established to help finding one's way through the maze of online resources. The idea behind this is to go beyond amending the present system, which is mainly based on the reputation of the journal or publisher - a system that says something about the publication process and culture, but not too much about the usefulness of a contribution to the scholarly debate. True, one can speculate about the prospective usefulness, connectivity or creativity of a material before publication, but it is surely better done only after publication, that is, when it is actually used by the target audience. Post-publication commenting or rating or usage tracking in various forms may help researchers as readers to assess the material they want to build on in their own work and may improve on the current (contentious) citation counts (Nentwich, 2003: 381; 1999).
'Political scientists should not let the software developers dominate when it comes to designing their future work space'.

\section{HOW SHOULD POLITICAL SCIENCE PROFESSIONALS REACT TO THIS DEVELOPMENT?}

Based on the above observations, the following are recommendations aimed to prepare the discipline for the age of 'cyberscience' (more general recommendations are to be found in, e.g., Nentwich, 2003: 465ff.):

- Accept genuine electronic publishing as equal to print publishing provided that the same standards of quality control are applied, for example, when it comes to research assessment exercises or tenure track evaluations.

- Support the open access movement, for example, by lobbying publishers (also professional associations that act as publishers) to become the so-called ROMEO green publishers, ${ }^{20}$ allowing self-archiving of book contributions and journal articles.

- Press for high-quality E-journals to be accepted by all indexing services, including the most widely used social science citation index (SSCI). Despite being widely used (and partially accepted as a viable yardstick), this private company has no transparent procedures when it comes to online journals.

- Make book contributions and other print material that are now underrepresented in the online world available on digital platforms to avoid the risk that print-only contributions in the 
field will be neglected once a certain threshold of online publications is reached.

- Support-archiving activities, such as institutional repositories or disciplinewide archiving server along with the necessary infrastructure for long-term archiving to make sure that all elements of the scientific discourse will be available for future reference; in addition, support the use of permanent resource locators, such as the DOI system to avoid the pitfalls of a fastdeveloping Internet that permanently reconfigures its files according to improved standards.

- Initiate and support intellectually, financially and personally, common endeavours to organise the virtual space of digital resources for, and research results of, political scientists in a flexible, but systematic and collectively endorsed way. In particular, new ways of quality filtering should be explored and the cooperation with regard to common virtual libraries be reinforced.

- Give credit for the time invested by scholars to improving cyberspace and to making it more suitable for the purposes of political science in particular.

- Support new, creative and potentially revolutionary publishing schemes, such as hybrid or virtual journals or 'living reviews' in order to test their usefulness for enhancing and improving scholarly communication in the future.

Unless the discipline actively engages in developing and shaping its cyberspace, the political science community will underachieve. The possibilities are more promising than just googling for a wikipedia definition or the E-mail address of a colleague! Political scientists should not let the software developers dominate when it comes to designing their future work space.

\section{Notes}

1 See http://www.politikon.org.

2 See http://www.ciaonet.org.

3 See http://www.vifapol.de.

4 See http://sosig.ac.uk/politics.

5 See http://rzblx1.uni-regensburg.de/ezeit.

6 See http://muse.jhu.edu/journals/subject.htmI\#philsci.

7 See http://www.doaj.org/ljbs?cpid $=47$.

8 See the Living Reviews Portal of the Max Planck Society: http://www.livingreviews.org.

9 Living Reviews in European Governance (LREG): http://europeangovernacne.livingreviews.org.

10 http://www.inst.at/trans.

11 For an example, see the Virtual Journals in Science and Technology (VJS) at http://www.virtualjournals. org.

12 http://oa.mpg.de/openaccess-berlin/berlindeclaration.html.

13 http://www.sherpa.ac.uk/romeo.php.

14 http://www.wellcome.ac.uk/node3302.html.

15 Communication from the Commission on scientific information in the digital age: access, dissemination and preservation, COM (2007) 56, http://ec.europa.eu/research/science-society/document_library/ pdf_06/communication-022007_en.pdf.

16 The European Research Papers Archive at http://eiop.or.at/erpa makes available for free a growing number of high quality working paper series.

17 The Social Science Research Network at http://www.ssrn.com.

18 The Archive of European Integration, hosted by the University of Pittsburgh, at http://aei.pitt.edu.

19 See in particular arXiv at http://arxiv.org.

20 The ROMEO database lists the policies of the major publishers of the world with regard to the intellectual property rights that authors retain when publishing with them. A 'green' publisher allows the 
parallel upload of the published article in an institutional repository; cf. http://www.sherpa.ac.uk/ romeo.php.

\section{References}

Calise, M. and Lowi, T.J. (2000) 'Hyperpolitics - hypertext, concepts and theory-making', International Political Science Review, July: from manuscript.

De Rosa, R. (2000) 'Political science scholarly sources on the Web: what, where and why?', IPSA (1-5 August 2000): Quebec.

Keller, A. (2001) 'Future development of electronic journals: a Delphi survey', The Electronic Library 19(6): 383-396.

May, C. (2005) 'The academy's new electronic order? Open source journals and publishing political science', European Political Science 4(1): 14-24. Online Available http://www.palgrave-Journals.com/ eps/journal/v4/n1/abs/2210004a.html.

Nentwich, M. (1999) 'The European research papers archive: quality filters in electronic publishing', Journal of Electronic Publishing 5: 1. Online Available http://www.press.umich.edu/jep/05-01/ nentwich.html.

Nentwich, M. (2000) 'The Future of Academic Knowledge Representation in the Age of Cyberscience', American Political Science Association (APSA) Annual Meeting, Panel "Information Technology and Political Science Research" (31 August -3 September 2000): Washington, DC. Online Available http://www.oeaw.ac.at/ita/ebene5/dsk/APSA/.

Nentwich, M. (2003) Cyberscience: Research in the Age of the Internet, Vienna: Austrian Academy of Sciences Press. Online Available http://hw.oeaw.ac.at/3188-7.

Nentwich, M. (2005) 'Quality control in academic publishing: challenges in the age of cyberscience', Poiesis \& Praxis. International Journal of Ethics of Science and Technology Assessment 3(3): 181-198. Online Available http://dx.doi.org/10.1007/s10202-004-0071-8.

Universitätsbibliothek Regensburg. (2006) Elektronischen Zeitschriftenbibliothek: Jahresbericht 2005. Regensburg. Online Available http://rzblx1.uni-regensburg.de/ezeit/anwender/Jahresbericht_ EZB_2005.pdf (April).

\section{About the Author}

Dr Michael Nentwich is Director of the Vienna Institute of Technology Assessment (Austrian Academy of Sciences). He previously worked at the Vienna University of Economics, in Warwick, Essex and the Max Planck Institute in Cologne. He studied law, political science, economics and science and technology studies. His main research interests are European integration and technology assessment. His volume on Cyberscience appeared in 2003. 